\title{
LECTURA DE DOS RELATOS DE CIENCIA FICCIÓN COSTARRICENSE: "ÓRDAGO" Y "OBJETO NO IDENTIFICADO”
}

Alí Viquez Jiménez.

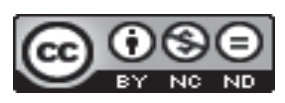

Esta obra está bajo una licencia Creative Commons Reconocimiento-No Comercial-Sin Obra Derivada 



\title{
LECTURA DE DOS RELATOS DE CIENCIA FICCIÓN COSTARRICENSE: "ÓRDAGO" Y "OBJETO NO IDENTIFICADO"
}

\author{
READING OF TWO COSTA RICAN SCIENCE FICTION STORIES: \\ “ÓRDAGO” AND “OBJETO NO IDENTIFICADO”
}

\author{
Alí Víquez Jiménez
}

\begin{abstract}
RESUMEN
Este artículo compara dos relatos de ciencia ficción costarricenses: "Órdago", de Manuel Delgado, y "Objeto no identificado", de Laura Quijano. Establece un contraste entre la orientación distópica de uno y la utópica del otro, pero también subraya la compatibilidad que los textos presentan al desechar la noción de Providencia.

Palabras clave: Ciencia ficción, literatura costarricense, utopía literaria, distopía literaria, providencialismo.
\end{abstract}

\begin{abstract}
This article compares two Costa Rican science fiction short stories: "All Out" by Manuel Delgado and "Unidentified Object" by Laura Quijano. It ascertains a contrast between the dystopian orientation of the former and the utopian angle of the latter. It also highlights the compatibility of both texts by rejecting the notion of Providence.

Key words: Science fiction, Costa Rican literature, literary utopia, literary dystopia, providentialism.
\end{abstract}

Me propongo elaborar las lecturas de dos relatos que forman parte de una segunda colección de cuentos de ciencia ficción publicada por la Editorial de la EUNED en su colección Vieja y nueva narrativa costarricense. La primera colección es de 2009 y se titula Posibles futuros. Cuentos de ciencia ficción; la segunda es de 2011 y se titula Objeto no identificado y otros cuentos de ciencia ficción. En ambos casos, se trata de grupos de cuentos de autores diversos (once, en total), todos pertenecientes a la nueva ola de escritores ticos interesados en la ciencia ficción, la mayoría muy jóvenes o, en todo caso, jóvenes como autores de literatura. He elegido dos relatos que me parecen comparables por razones que haré explícitas posteriormente: “Órdago”, de Manuel Delgado (2011) y “Objeto no identificado”, de Laura Quijano (2011).

M.L. Alí Víquez Jiménez. Universidad de Costa Rica. Profesor de la Escuela de Filología, Lingüística y Literatura. Costa Rica.

Correo electrónico: aviquez@yahoo.com

Recepción: 02- 10- 2013

Aceptación: 15- 03- 2014 


\section{Religión y destrucción en “Órdago”, de Manuel Delgado}

En "Órdago", Manuel Delgado (2011) elabora el relato de la creación de una mitología religiosa tomando la perspectiva del "dios" responsable de tal, que viene a ser un hombre de carne y hueso, sobreviviente a duras penas de una catástrofe que ha acabado con la inmensa mayoría de la humanidad. El planteamiento que permite tal es el siguiente: por razones que encuentran su raíz en la destructividad propia de los seres humanos, estos han provocado un cataclismo total del planeta Tierra. Los detalles no se explican en este relato, pero sí está claro que es la especie humana, como colectividad, la que se carga con la responsabilidad, tajantemente asignada en la última frase del texto. Un grupo de personas ha logrado huir a bordo de una inmensa nave llamada "Ra"; aquí no se explica demasiado esta historia madre, pero recordemos que el mismo Delgado escribe la novela El vuelo del Ra (2010).

Una pequeña nave, en la que viajaba un número mucho menor de personas, se ha desprendido del $\mathrm{Ra}$ y ha aterrizado en el planeta en que tendrá lugar la narración, y ahora sus dos ocupantes (pues los demás han muerto ya) tratan de retomar el contacto con el Ra, para lo cual deberán abastecerse de ciertos materiales no especificados, pero que se hallan en las minas del planeta. Se dedican entonces a esta tarea de extracción y procesamiento del contenido de las minas que les permitiría volver a contactar la nave madre en que se encuentran los otros seres humanos. En el transcurso de tal, los personajes, marido y mujer, entran en contacto con una especie de homínidos autóctonos: pigmeos de tez oscura cuya suerte evolutiva se habría desarrollado de manera independiente para dar lugar a una especie enteramente similar a la humana, pero que se encuentra en un estadio primitivo en el cual ni siquiera han aprendido a servirse del fuego. En el relato, no se explica cómo ha podido producirse esa enorme "coincidencia evolutiva", de modo que en un planeta distante de la Tierra se hallen seres humanos primitivos; sí se alude a que el propio protagonista y narrador alberga fuertes reservas para admitirlo: "Más me costó aceptar la evidencia de que más que homínidos, aquellos pigmeos eran homininos, no simples primates venidos no se sabe de dónde, sino seres humanos, si es que puede llamarse humano algo que exista de este lado del universo" (Delgado, 2011, p. 21). El narrador y su esposa, preocupados como están en procurarse el contacto con la nave madre, tampoco paran mientes en la investigación de las raíces evolutivas de la especie autóctona. Aunque hay que añadir que es él quien se interesa menos en los nativos, y si lo hace, de manera descuidada y tardía, parece ser a instancias de ella, mucho más sensible al contacto con los primitivos habitantes que los rodean.

La narración gira en torno al hecho de que la figura del narrador se convierte en objeto de culto religioso entre estos nativos. La displicencia del personaje que se endiosa es tal que este no se da cuenta de lo ocurrido hasta que su esposa se lo hace ver, y aún entonces, al principio, atribuye la opinión de la mujer a su proclividad hacia las fantasías: "No quería darle crédito a mi mujer", afirma, para luego verse forzado a dudar de sus motivaciones profundas: "O quizá tenía miedo a ese crédito, a esa convicción incómoda y comprometedora de sentirse considerado superior y, por tanto, responsable de destinos ajenos" (Delgado, 2011, p. 21).

Toda la narración, en boca de este "dios", apunta al hecho de que, en caso de que algún fin trágico no llegue a interrumpir el devenir de esta especie de humanos en ciernes (se apunta a la posibilidad de pandemias tanto como al probable incremento de la violencia interna), la presencia de esta pareja de dioses (más él que ella) daría lugar a la creación de una mitología religiosa en el porvenir del planeta. El texto, pues, pretende constituirse como la explicación de 
las futuras elaboraciones religiosas, la aclaración de cuál sería la semilla de la que brotará toda una mitología posterior. Se podría decir entonces que, mutatis mutandis, Manuel Delgado (2011) ha escrito un Génesis más auténtico que el Génesis bíblico, pues en primer lugar va más atrás: no se ocupa de la creación del mundo, sino de la más original creación del dios, y en segundo lugar, no ha sido escrita por creyentes o visionarios iluminados por el dios de marras (pero -al fin y al cabo- sus intermediarios), sino que proviene de la pluma directa del dios. Si el mundo es mundo porque lo creó un dios, la pregunta de cómo se creó ese dios, aunque tan elemental que podría estar en boca de un niño, no deja de meter en embrollos a los creyentes más avisados. El relato responde a esa pregunta de cómo se ha creado dios. Paradójicamente, este Génesis se presenta, como hemos visto, paralelamente al apocalipsis de la humanidad terrícola, que ha destruido su planeta y se encuentra diezmada abordo de la nave Ra.

A partir de la aclaración que el texto efectúa, se pueden inferir ciertas características posiblemente generalizables hasta cierto punto a todo fenómeno religioso visto en profundidad. Ese punto al que pueda llegar esta generalización no es mi objeto de estudio, ya que creo que la literatura es más un espacio para la sugestividad que para la comprobación de tesis antropológicas. He aquí las implicaciones del texto de Manuel Delgado que me parecen más importantes:

a. La más evidente es sin duda que el dios no es un dios. Los nativos se encargan de divinizar al extranjero, pero este no tiene de dios ni un ápice. Su historia personal es tan trágica como la del más desamparado de los seres humanos, juguete de un destino que le ha quitado a sus hijos junto con todo el mundo del que formaba parte, primero, y poco después a su mujer, que había logrado sobrevivir con él.

b. El falso dios es completamente indiferente ante las necesidades, ruegos o expectativas de quienes lo adoran. Más allá incluso, el narrador manifiesta a menudo cierta repugnancia ante las criaturas que lo reverencian, y si alguna vez los ayuda, no es por habérselo propuesto, sino porque le ocurrió por descuido o casualidad, o bien por el interés personal: se dedica a erradicar una plaga cuando cree que la enfermedad se podría tornar peligrosa para él o su mujer. No lo mueve ningún sentimiento compasivo ante los nativos, ni mucho menos la solidaridad o la identificación con ellos.

c. Dentro de su indiferencia en lo profundo, caben en el falso dios respuestas emotivas más superficiales, que ocurren cuando las intervenciones de los nativos se tornan problemáticas para él o su mujer. Hay lugar entonces para la ira, que desemboca en el ejercicio de la violencia arbitraria, indiscriminada y sin cargo alguno de conciencia: el protagonista se permite dar muerte a todo aquel aborigen que le represente peligro o intromisión en su intimidad, y llega a tornarse en una fuerza castigadora demoledora. Hay lugar, en menor proporción, para el miedo y la culpa, tanto por sospechar que los nativos podrían ser incontrolables y atentar contra su esposa y él, como por la responsabilidad que el hecho de ser un dios ha puesto sobre sus hombros: "Enojo, sí", confiesa el narrador, "pero también era el sentimiento de culpa, el miedo a reconocer la responsabilidad de haber sembrado en aquellos primates el sentimiento de lo trascendente" (Delgado, 2011, p. 26).

d. Lejos de apaciguar la divinización del falso dios, el comportamiento violento de este parece fomentarla. Cuanto más agresivo se demuestra el narrador, más se le considera un dios, como si el lenguaje primordial del cual la religión se vale fuese el de la intimidación. 
Esta podría ser incluso la razón por la cual la divinización se da en torno principalmente al personaje masculino, el cual es aquel que está dispuesto a tomar vidas de los nativos, mientras que la mujer, que no los mata, no es objeto de culto al grado en que lo es su marido.

e. Las prácticas religiosas se traducen básicamente en dos respuestas: la fetichización y la violencia, acaso motivada por el miedo. Los nativos crean una serie de fetiches mediante los cuales pretenden un acercamiento a su dios iracundo y muy poco comunicativo, como si desearan proveerse de un lenguaje con el cual hablarle y apaciguar su cólera; al mismo tiempo, aprenden de la conducta de su falso dios un comportamiento cada vez más violento, que a la postre se traducirá en el asesinato de Brenda: "Entonces me di cuenta de que entre el miedo de los aborígenes y el mío, la distancia se había reducido considerablemente, quizá menos de lo permisible. Antípodas como éramos, él nos unía, nos hacía iguales, tiraba de nosotros hasta caminos desconocidos de furia y violencia” (Delgado, 2011, p. 29).

f. Interesantemente, un primer movimiento, totalmente involuntario, ha sido el desencadenante de la divinización del narrador, y este movimiento ha sido solidario. Estamos ante la evocación de la figura de Prometeo, que entrega el fuego a los seres humanos: "[...] fuimos enseñando a aquellos seres desagradables todavía en aquellos primeros días de contactos (¿es que no son más desagradables ahora?) cosas que les resultaron útiles. No sé cómo ocurrió, quizá de un descuido mío, quizá por mera coincidencia, lo cierto es que estos pequeños primates empezaron a entender la importancia del fuego" (Delgado, 2011, p. 24). Pero, como hemos visto, la solidaridad del dios se verá severamente limitada por su tendencia al comportamiento violento.

g. El proceso de divinización a que se ve sometido el narrador le pasa una factura psicológica, al punto que su propia esposa comienza a dar muestras de preocupación por su salud mental. El endiosado comienza a creer en sus propios poderes divinos, que no son posibilitados, por supuesto, por ningún poder sobrenatural sino por una tecnología bélica mucho más desarrollada que la de los nativos, y se acostumbra a enviar terremotos, fuego o inundaciones como lo haría un dios verdadero. El narrador no llega a perder del todo la razón, pues tiene la sensatez de continuar con su plan de abandonar el planeta, incluso luego de que su esposa ha sido asesinada y comida por los nativos y él se siente proclive a castigar con una destrucción total el pecado de la teofagia.

h. La esperanza en la inmortalidad se yergue como sospecha en todo este proceso de divinización. No hay certeza al respecto, pero da la impresión de que los nativos quisieran ver en su falso dios a un posibilitador de la trascendencia personal, esperanza completamente inútil a la vista de las capacidades más bien únicamente destructivas del narrador.

i. El germen de la hominización se da conjuntamente con el de la divinización, al que se llama su correlato, y que lleva como implicación nefasta el ejercicio de los poderes destructivos de la especie. El texto puede leerse como una propuesta en este sentido: los seres humanos, en su busca de la inmortalidad personal y de la trascendencia hacia los dioses que desemboca en las prácticas religiosas, se ven inevitablemente envueltos en actos violentos que, lejos de convertirlos en inmortales, aceleran la destrucción de sus precarias existencias. La religión lleva consigo la semilla del cataclismo de lo humano. 
j. Incapaz de traducirse en un cambio definitivo, aparece sin embargo aquí la figura de la mujer, compasiva, fantasiosa y solidaria. Brenda es una superviviente "a regañadientes" del planeta Tierra, y representa a un grupo que al parecer se extingue con ella: poetas, filósofos y creadores que pierden la batalla frente a quienes se arman de violencia para participar en la determinación de los destinos y decidir el rumbo de la humanidad.

Una aclaración final en cuanto al título. Este se compone de una sola palabra que jamás se menciona en el texto, lo que aumenta el margen para una lectura abierta, es decir, no se da una programación de lectura cerrada en cuanto a cómo habría de interpretarse. "Órdago" es una apuesta, una jugada arriesgada en el juego del mus, en la cual se juega el todo por el todo, lo que tal vez apunte al azar implicado en la posibilidad final de que el narrador retorne a Ra, tanto como a lo que pueda acontecer por mera casualidad en el devenir histórico de la hipotética cultura religiosa que el narrador deja atrás en el planeta que abandona a su suerte, luego de sembrar en él el camino autodestructivo que su propia humanidad (vale decir, la de los terrícolas) ha querido seguir.

\section{Azar y conservación en “Objeto no identificado”, de Laura Quijano}

En este relato, nos ubicamos primeramente en la Costa Rica de finales de siglo XXI, en el momento en que está a punto de talarse el último de los bosques primarios del país, pese a la oposición de algunos, que en el texto se presentan en la figura de dos personajes, José y Camila. La narración está focalizada en la perspectiva de esta última, una ambientalista joven, aunque no tanto como él, diez años menor. En la última parte del relato, nos trasladamos a los "días postreros del siglo XXV", y entramos en contacto con dos personajes, uno de los cuales, el femenino, se nos revelará como una descendiente de la primera Camila, y es a través de ella (la gobernadora) que se focaliza la narración restante.

Las observaciones sobre las cuales elaboro mi lectura de este relato son las siguientes:

a. Pese a lo que se podría prestar a ser interpretado como un signo muy visible del camino hacia la destrucción planetaria, cual es la pronta desaparición del último de nuestros bosques vírgenes, en el texto se comienza por relativizar la dimensión de esta supuesta catástrofe, al punto que la propia Camila admite que la decisión de un tribunal acerca de permitir esta destrucción no carece de cierta dosis de razón: se nos explica cómo se han implantado una serie de medidas de compensación de las pérdidas ecológicas, al tiempo que la explotación de este bosque primario conllevaría grandes beneficios económicos. El texto, pues, lejos de asumir una bandera propagandística unilateral que podríamos llamar de "alegato ecológico", se plantea dentro de un discurso de mayor frialdad racional, que analiza los pros y los contras prácticos de la preservación de un bosque primario en particular. Diríase que se trata de un discurso pragmático que incluso visualiza y hasta cierto punto censura, sobre todo en la figura de José, al personaje ambientalista que se deja controlar por sus impulsos emocionales, no siempre correctos.

b. El planteamiento anterior solamente es posible dentro de una visualización del desarrollo y del futuro de la humanidad no tremendista. Al presentarnos las postrimerías del siglo XXI, el panorama no es de desolación ni de acusación por los perjuicios que el desarrollo económico le habría causado a los ecosistemas. Más bien parece que la humanidad ha encontrado fórmulas que, si bien no son perfectas, sí han posibilitado un equilibrio entre el desarrollo económico y la preservación del ambiente. La cita siguiente, aunque muy 
extensa, me parece imprescindible para retratar este planteamiento, que no carece de matices paradójicos de los cuales el propio texto es muy consciente y no deja de subrayarlos:

\begin{abstract}
Lo peor de sus sentimientos mezclados era que no culpaba al tribunal por haberles negado la razón. Después de todo, era consciente de las paradojas inmensas de la vida. El bosque era, a pesar de lo increíble que parecía a aquellas alturas del siglo XXI, un bosque primario. Su vegetación, sus especies animales, sus intrincados ecosistemas eran originales. Estaba allí desde cientos de miles, quizás millones de años atrás. Pero no producía beneficios directos para las comunidades humanas que habitaban sus cercanías. [...] En cambio, la compañía energética que había ganado la propiedad sobre él venía a desarrollar grandes cultivos que proveerían un importante porcentaje de suministros a los biocombustibles del país. Representaba empleo y prosperidad para la comunidad, ahorro energético y otros beneficios. Con sus nuevas tecnologías, era capaz de replantar otros terrenos, salvaguardar la atmósfera del exceso de dióxido de carbono, no ensuciar las aguas ni desgastar las tierras o contaminarlas con químicos. Tampoco era una amenaza de erosión. Y ahí estaba la paradoja: salvaguardando el medio ambiente, destruía el medio ambiente. Pero la destrucción de uno era menor a la creación del otro, en términos prácticos. ¿Cómo defender entonces el bosque? Camila sabía la respuesta: no habían podido. El único argumento que quedaba era sentimental, pues hasta el Reservorio Genético Nacional contenía la información suficiente para recrear el bosque entero si era necesario. (Quijano, 2011, p. 82)
\end{abstract}

Así pues, el texto no pasa por alto la necesidad de tomar en cuenta, en cualquier plan de desarrollo, la valoración de los aspectos económicos junto con la de los ecológicos. Además, su lectura del futuro se puede calificar de optimista, pues propone la creación de nuevas tecnologías sumamente capaces de reparar los daños que el desarrollo económico conlleve. (Por otra parte, en la última sección del relato, se nos adelanta la previsión de que la longevidad promedio de los seres humanos se seguirá incrementando, tal como ha ocurrido en los últimos tiempos. Ello porque aparece el personaje del doctor Salinas, que en el siglo XXV no sólo ha sobrepasado los cien años de edad, sino que permanece activo laboralmente y parece gozar de excelente salud física y mental).

c. No obstante el anterior planteamiento inicial, la continuación del relato nos enfrenta con la debilidad que este demuestra tener. Debilidad relativa, no absoluta. Pues los acontecimientos siguientes demuestran el error en el que se ha incurrido al menos en una de las aseveraciones transcritas: el bosque no se podía recrear tal cual por parte del Reservorio Genético Nacional, sin pérdida de alguna información que resulta ser muy valiosa. Cuando, por causas que el relato nos aclarará, el bosque no se destruye, ello redunda en el "[...] descubrimiento de nuevas especies y el inesperado hallazgo de curas sorprendentes contra enfermedades degenerativas, lo que había convertido al bosque en "indispensable" después de todo, cuando antes había sido considerado "descartable"” (Quijano, 2011, p. 92-93).

d. El azar cumple un papel determinante en la conservación del bosque. Es por un mero accidente, generado en el siglo XXV, como se dan las circunstancias que en ese final del siglo XXI obstruyeron su inminente desaparición. Hay una suerte de "efecto mariposa" afortunado que presenciamos en este relato, con la particularidad de que ocurre con una inversión en la dirección del tiempo: un acontecimiento sin mayor importancia en el futuro (la pérdida de unos objetos al fin y al cabo nada valiosos, en el marco de experimentos que sí son relevantes, pero en los cuales la pérdida de los objetos en sí misma no interesa) hace sentir sus efectos en el pasado, efectos multiplicados al punto de llegar a producir algo tan importante como lo que hemos visto.

e. El golpe de suerte se articula de manera muy positiva con una realidad nacional no carente de problemas debidos a la impericia con que opera nuestra organización política. El texto 
señala la falta de leyes en la Costa Rica de finales de siglo XXI para proteger debidamente al medio ambiente, y en cambio la vigencia de leyes que tratan de preservar el patrimonio arqueológico de entonces, leyes no censurables aunque posiblemente exageradas en nuestro contexto, y surgidas por razones equivocadas. Habla Camila:

\footnotetext{
[...] acuérdate del tremendo descubrimiento de la ciudad perdida en el Mar del Norte, en el 2020 o por ahí [...] Aquí se pusieron como locos, a excavar y todo eso, como si fuéramos a encontrar otra ciudad perdida debajo de las piedras -y se echó una sonrisa sarcástica-. De pronto los indígenas fueron seres venidos de otro planeta que fabricaron esferas de piedra para marcar "pistas de aterrizaje" o alguna tontería similar. Por eso se aprobó la ley de 2024 [...]. (Quijano, 2011, p. 88)
}

f. La interpretación de este azar benefactor excede las posibilidades racionales de los personajes involucrados en la narración. Posiblemente, el más equivocado al respecto sea José, el jovencísimo ambientalista que, al celebrar la aparición de las estatuillas misteriosas que produjeron la preservación del bosque, no duda en pensar que estas deben calificarse de "providenciales"; es decir, José atribuye a una disposición anticipada en procura de la preservación del bosque lo que no ocurre sino por causa del azar. En cuanto a la Camila del siglo XXI, su incapacidad para explicarse la presencia de las estatuillas le produce desazón y hasta temor, al punto que prefiere desligarse incluso del estudio del bosque finalmente preservado, con tal de abandonar las preocupaciones que este misterio le provoca. Queda, por otra parte, la Camila del siglo XXV, quien es la que poseería la clave para explicar racionalmente todo lo ocurrido, pues llega a asociar los bloques de piedra desaparecidos en el experimento del siglo XXV que le explica el doctor Salinas, con las viejas estatuillas aparecidas sin explicación en el siglo XXI, hallazgo en el cual estuvo involucrada una de sus ascendientes. Ella sospecha que en el experimento de teletransportación del doctor Salinas en el siglo XXV se extraviaron en el espacio-tiempo esas piedras que habían sido encontradas en el siglo XXI por la Camila de entonces. Pero digo que la Camila del siglo XXV "poseería" esa clave, en condicional, porque se rehúsa a darle crédito alguno, al considerar descabellada la idea y atribuirla a la influencia perniciosa de la ciencia ficción. El relato cierra con la paradoja de que la verdad se halla en esa supuesta fantasía inducida por las "mentiras" de esta clase de arte.

g. La traza de los destinos humanos se visualiza pues como el resultado de las múltiples variables del azar: un elemento particular que refuerza esta propuesta general puede leerse en el hecho de que la Camila del siglo XXI se decide a casarse movida por los acontecimientos aquí narrados: "[...] se había reencontrado con su antiguo novio de la facultad y se había casado con él en un explosivo impulso romántico, inconcebible antes del hallazgo" (Quijano, 2011, p. 93). Adivinamos que la Camila del siglo XXV debe en parte su existencia a esta unión matrimonial, es decir, en el fondo, al enigmático encuentro de las estatuillas.

h. La importancia del azar debe sin embargo relativizarse, pues no deja de resaltarse en este texto el hecho de que, junto al azar, existe la voluntad humana, responsable (aunque no sin ayuda de la suerte) por el desarrollo tecnológico que apunta en términos generales al mejoramiento de la civilización. Es una cuestión de actitud: "No sería ella la primera Camila de su familia que se echaría atrás ante la adversidad. Siempre habría otros caminos, otras soluciones" (Quijano, 2011, p. 97). El texto, así, apunta hacia una visión de mundo en la cual el azar es un factor hasta cierto punto controlable pero hasta cierto punto también incomprensible. 


\section{La comparación}

Al visualizar conjuntamente ambos textos, saltan a la vista los siguientes contrastes:

a. Delgado (2011) elabora una propuesta apocalíptica acerca del destino de la humanidad, dadas las tendencias destructivas dominantes en esta como colectividad. Quijano (2011), al contrario, prevé un futuro humano en el cual se encuentra cierto equilibrio entre los factores que intervienen y que posibilita un mejoramiento general.

b. Dadas las orientaciones anteriormente señaladas, el relato de Delgado se elabora con recurso a una narración estructurada sobre la lógica del principio y el fin de lo humano: Delgado alude al Génesis y al Apocalipsis. Por el contrario, Quijano elabora una narración dentro de una continuidad de lo humano, que no conoce en su texto ni principio ni fin.

c. Delgado identifica lo humano con lo predominantemente destructivo, mientras que Quijano lo identifica con lo predominantemente constructivo. Hablamos, eso sí, de predominancias, pues también Delgado reconoce (sobre todo en el personaje de la mujer) la capacidad creadora y solidaria del ser humano, así como Quijano plantea los riesgos de la imprudencia destructiva de este, cuyos razonamientos para justificarse pueden calificarse al menos en ocasiones de erróneos, lo que implica cierta ceguera y cierta soberbia.

d. La dimensión acordada a los problemas que enfrenta la humanidad en estas dos versiones de futuro (no olvidemos que la primera de las colecciones publicadas por la Editorial EUNED se tituló Posibles futuros) es ciertamente contrastante: mientras que Delgado plantea una cantidad de problemas tales que sólo queda la esperanza del último aleteo de una nave espacial, Quijano plantea problemas ciertamente más manejables en el contexto del siglo XXV: "Sobresaturación de vías de transporte, exceso de tamaño en los transbordos de carga, nueva búsqueda de combustibles alternativos para los viajes al espacio exterior, sobrepoblación en centros urbanos [...]" (Quijano, 2011, p. 97).

No obstante estos contrastes, encuentro una afinidad filosófica profunda entre ambos relatos, con lo cual concluyo mi aproximación a ellos. Se trata de que en los dos casos nos enfrentamos a un desplazamiento de la noción de Providencia hacia la noción de un azar dominante. Todo el texto de Delgado es una reescritura del origen de una mitología religiosa, que ciertamente implica la inexistencia del factor providencial, en el sentido de atribuible a una voluntad divina, en favor del factor azaroso, que determina la aparición de la creencia religiosa únicamente por la casualidad de un viaje hacia un destino indeterminado. Asimismo, el texto de Quijano construye un mundo en el que el azar no se rinde a la Providencia, sino que a lo sumo puede verse atenuado por la intervención humana, que sin embargo no parece alcanzar a ser determinante: somos hijos de un azar que nuestra inteligencia no consigue siempre descifrar por completo, pero sin abandonar nuestra voluntad de modificarlo a nuestro favor.

Aunque predominantemente pesimista uno y predominantemente optimista el otro, Manuel Delgado y Laura Quijano comparten el gesto que, desplazando a Dios del panorama del universo, pone a la humanidad a lidiar con un destino azaroso. 


\section{Bibliografía}

Casasa, L. et ál. (2009). Posibles futuros. Cuentos de ciencia ficción. San José: Editorial Universidad Estatal a Distancia.

Castillo, M. et ál. (2011). Objeto no identificado y otros cuentos de ciencia ficción. San José: Editorial Universidad Estatal a Distancia.

Editorial Universidad Estatal a Distancia. (2014). Vieja y nueva narrativa costarricense (129-147). San José: Autor.

Delgado, M. (2010). El vuelo del Ra. San José: Uruk editores.

Delgado, M. (2011). Órdago. Por M. Castillo et ál. Objeto no identificado y otros cuentos de ciencia ficción. (21-31). San José: Editorial Universidad Estatal a Distancia.

Quijano, L. (2011). Objeto no identificado. Por M. Castillo et ál. Objeto no identificado y otros cuentos de ciencia ficción. (81-97). San José: Editorial Universidad Estatal a Distancia. 
